\title{
Ibrahim Kanalan
}

\section{Die universelle Durchsetzung des Rechts auf Nahrung gegen transnationale Unternehmen}

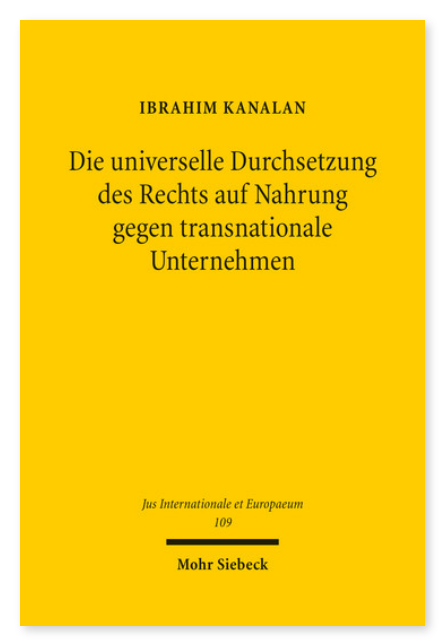

2015. XIV, 457 Seiten. JusIntEu 109

ISBN 978-3-16-154092-9

DOI 10.1628/978-3-16-154092-9

eBook PDF 94,00€

ISBN 978-3-16-154048-6

fadengeheftete Broschur 94,00€
Ibrahim Kanalan widmet sich der Bekämpfung von Hunger. Er geht der Frage nach, ob das Recht auf Nahrung universell einklagbar ist und gegen transnationale Unternehmen durchgesetzt werden kann. Er setzt sich grundlegend mit den Einwänden auseinander, die gegen die universelle Justiziabilität sozialer Menschenrechte eingebracht werden. Mit einer ausführlichen Analyse der verschiedenen globalen Normen sowie der Rechtsprechung auf internationaler, regionaler und nationaler Ebene zeigt der Autor, dass das Recht auf Nahrung universell einklagbar ist. Sodann systematisiert er die verschiedenen Rechtsansprüche in Auseinandersetzung mit der fragmentierten Spruchpraxis zahlreicher Gerichte und quasigerichtlicher Organe. Ibrahim Kanalan entwickelt ein neues und unkonventionelles Konzept, mit dem er die unmittelbare Bindung von Unternehmen an die Menschenrechte begründet. Von einem rechtspluralistischen Verständnis ausgehend analysiert er abschließend verschiedene Möglichkeiten der transnationalen Durchsetzung des Rechts auf Nahrung.

Ibrahim Kanalan Geboren 1980; Studium der Rechtswissenschaften an der Freien Universität Berlin; Referendariat am Kammergericht Berlin; 2014 Promotion (Universität Bremen); derzeit wissenschaftlicher Mitarbeiter am Lehrstuhl für Öffentliches Recht und Völkerrecht an der Universität Erlangen-Nürnberg.
Jetzt bestellen:

https://mohrsiebeck.com/buch/die-universelle-durchsetzung-des-rechts-auf-nahrung-gegen-transnationale-unternehmen9783161540929?no_cache=1

order@mohrsiebeck.com

Telefon: +49 (0)7071-923-17

Telefax: +49 (0)7071-51104 